\title{
Cambio Climático adverso provocado por la urbanización sin planificación ni evaluación ambiental en Santiago de Chile
}

\author{
Adverse Climate Change caused by the urbanization \\ without environmental planning and assessment in \\ Santiago de Chile
}

\author{
Flávio Henrique Mendes ${ }^{1}$ (1), Hugo Romero² (1) y \\ Demóstenes Ferreira da Silva Filho ${ }^{3}$ (i)
}

\begin{abstract}
RESUMEN
A pesar de modelos y evidencias científicas disponibles sobre el Cambio Climático a escala global, la planificación y gestión de los territorios urbanos en Latinoamerica no ha conseguido considerarlo por sobre sus restricciones económicas, sociales y políticas. Seleccionando la temperatura superficial y la ventilación como variables climáticas críticas se analiza el caso de Santiago de Chile como ejemplo de contradicciones entre políticas y declaraciones oficiales y las transformaciones reales de los climas urbanos, destacando el incremento generalizado de las temperaturas de superficie, representado por imágenes satelitales, debido a la ausencia de evaluaciones ambientales rigurosas de cambios de usos y coberturas de suelos que han acompañado la urbanización. Una simulación microclimática ha permitido estimar la reducción de velocidad y cambios en la dirección de los vientos, como consecuencia de la densificación y verticalización en la comuna de Estación Central. La generación de "zonas muertas" de ventilación se relaciona con diseños, topología y exposición de las edificaciones, afectando la calidad de vida de los habitantes. La mitigación y adaptación a lo Cambio Climático debe formar parte explícita de los objetivos, planes y proyectos que persigan la calidad y justicia territorial de los climas urbanos y, consiguientemente, del bienestar y confortabilidad de la sociedad.
\end{abstract}

Palabras clave: clima urbano, imágenes Landsat-7, temperatura de superficie, ventilación, ENVI-met.

\begin{abstract}
Despite available models and scientific evidence on climate change on a global scale, the planning and management of urban territories in Latin America has failed to consider it above its economic, social and political constraints. By selecting surface temperature and ventilation as critical climate variables, the case of Santiago de Chile is analyzed as an example of the contradictions between policies and official declarations and the real transformations of urban climates, highlighting the widespread increase in surface temperatures, represented by satellite imagery, due to the absence of rigorous envi-
\end{abstract}


ronmental assessments of changes in land uses and covers that have accompanied the urbanization. A microclimatic simulation has allowed estimating the reduction of speed and changes in the direction of the winds, such as consequence of the densification and verticalization in the Estación Central commune. The generation of ventilation "dead zones" relates to designs, topology and exposure of the buildings, affecting the quality of life of the inhabitants. Mitigation and adaptation to Climate Change should be an explicit part of the objectives, plans and projects that pursue the quality and territorial justice of urban climates and, consequently, the well-being and comfort of society.

Keywords: urban climate, Landsat-7 images, surface temperature, ventilation, ENVI-met.

\section{Introducción}

Las ciudades constituyen el principal nicho ecológico de la humanidad, claramente afectada por la incertidumbre y pronósticos negativos asociados a las transformaciones ambientales causadas por un desarrollo inconsistente, frente a la constatación de datos empíricos y modelos de análisis del Cambio Climático y sus efectos sobre los espacios y sociedades urbanizadas que caracterizan la situación global contemporánea. Resulta incomprensible que, a pesar de la aceptación generalizada de que las ciudades son focos de generación y de concentración de los impactos del Cambio Climático, las evidencias existentes demuestren que no solo no se han aplicado medidas de mitigación y adaptación en forma permanente y sistemática en el diseño, planificación y gestión de los espacios geográficos urbanos, sino que, por el contrario, han aumentado y aumentan diariamente las transformaciones adversas al interior de las ciudades, tales como el incremento de las fuentes de calor fijas y móviles. Algo similar ocurre con la reducción de la humedad atmosférica debido a la desecación de humedales y el desaparecimiento de las áreas verdes y suelos saturados. De igual manera, el acceso de las masas de aire costeras o ribereñas se ve impedido crecientemente por la verticalización de las edificaciones de sus bordes. Adicionalmente, la ventilación, necesaria para mitigar el calor y depurar los contaminantes atmosféricos se reduce o desaparece como consecuencia de la obstrucción y encauzamiento de los flujos de aire causados por la altura y orientaciones de edificaciones que no consideran para nada la generación de cañones urbanos o zonas "muertas" a sotavento de las mismas. Las islas y olas de calor aumentan en vez de decrecer en las ciudades como consecuencia de las construcciones que almacenan la radiación solar y posteriormente la devuelven a las capas atmosféricas "límites" y de follaje o "canopia" urbano (Oke, 1978; Stewart \& Oke, 2012).

El crecimiento urbano incluye la pavimentación e impermeabilización de paisajes naturales, que sustituyen bosques, matorrales, humedales y campos agrícolas y forestales, sin límite ni consideración alguna por la conservación de los servicios ecosistémicos que prestan. La homogeneización de las zonas de calor y carentes de humedad elimina los contrastes térmicos necesarios para generar brisas y vientos locales, explicando en parte los altísimos niveles de concentración de contaminantes atmosféricos que en la actualidad se registran en lugares específicos de las ciudades grandes y medianas. Pareciera que los conocimientos existentes y la tarea sistemática de la investigación científica por proveer de mejores y mayores datos sobre los climas urbanos no son suficientes para alterar decisiones de diseño y planificación de las ciudades, que continúan siendo lideradas por la rentabilidad económica y las urgencias sociales. Consecuentemente, estas consideraciones no forman parte de las exigencias explícitas de conservar la calidad de los 
climas y del aire, ni de proponer acciones de justicia ambiental, confort y adecuada calidad de vida para sus habitantes (Romero, 2019).

Los objetivos específicos para contener el Cambio Climático no son parte de los instrumentos de planificación territorial y, en los casos en que se han generado redes de colaboración entre ciudades, terminan siendo totalmente efímeras, insignificantes e ineficaces frente a los requerimientos de los agentes económicos y políticos que controlan el desarrollo urbano. Barton (2009) realizó un detallado análisis de las propuestas, programas y proyectos internacionales sobre Cambio Climático que se habían presentado hasta fines de la primera década del siglo XXI, concluyendo que la resiliencia al clima debería ser el sine qua non de la planificación territorial de las regiones y las ciudades, debiéndose otorgar prioridad a la adaptación de los asentamientos humanos, en particular debido a la concentración espacial y vulnerabilidad de la mayoría de sus habitantes. Consideraba que el enfoque sectorial prevaleciente, orientado principalmente al fomento productivo y a las soluciones de infraestructura no era suficiente, siendo necesario que quienes toman decisiones en los centros urbanos dispusieran de la capacidad de coordinar respuestas adecuadas de corto, mediano y largo plazo a través de la planificación territorial y urbana, es decir, en casos sin planes de adaptación, como en la ciudad-región de Santiago de Chile, se puede notar el aumento de los riesgos asociados y de los costos para su reducción.

En el marco de la preparación de la Conferencia de las Partes del Programa Marco de las Naciones Unidas sobre Cambio Climático (COP25) que se debería haber celebrado en noviembre de 2019 en Santiago de Chile, un Comité Científico establecido por el Ministerio de Ciencia, Tecnología, Conocimiento e Innovación preparó el Informe "Ciudades y Cambio Climático en Chile: Recomendaciones desde la evidencia científica" (Muñoz et al., 2019). Los objetivos de este documento fueron reunir informaciones sobre políticas públicas relacionadas con el tema, analizar la situación de las ciudades chilenas en temas de mitigación (entre ellos movilidad, edificación, equipamientos y energía), adaptación (frente a riesgos y desastres, desarrollo de infraestructura, espacios verdes y vulnerabilidad en términos de salud) y gobernanza. Se trataba de presentar propuestas de acción destinadas a reducir las emisiones de gases invernadero producidas en las ciudades y la vulnerabilidad de los asentamientos humanos ante los desastres y riesgos socionaturales. Estas dos últimas acciones han sido planteadas como prioritarias en todas las iniciativas oficiales respecto a la lucha contra el Cambio Climático en las ciudades chilenas, concebidas más bien como receptoras pasivas de sus impactos. De acuerdo a los autores, en Chile, las políticas y planes han sido pocas y de reciente promulgación, como es el cado del Plan de Adaptación al Cambio Climático para Ciudades (PACC Ciudades), aprobado en 2018, pero que aún no se ha implementado (Muñoz et al., 2019). A la vez, ha habido iniciativas realizadas a través de la Organización No Gubernamental (ONG) ADAPT-Chile y la Red de Municipios frente al Cambio Climático que han desarrollado procesos de concientización, identificación de amenazas y medidas locales de enfrentamiento; también, proyectos del Banco Interamericano de Desarrollo (Programa Ciudades Emergentes y Sostenibles), de la Fundación Rockefeller (Santiago Humano y Resiliente) y el proyecto Clima-Adaptación-Santiago (CAS), financiado por el gobierno alemán entre 2009 y 2012, que contó con la participación de académicos y autoridades del gobierno regional, y el proyecto MAPA con apoyo del CIDE de Canadá.

Según este documento oficial destinado a informar a los delegados internacionales ante la COP25, la disponibilidad de conocimientos científicos que sustenten las medidas para enfrentar 
el Cambio Climático en las ciudades no es suficiente si no existen mecanismos adecuados para la toma de decisiones, que superen acciones parciales y desarticuladas. Es necesario, ante esto, una gobernanza que incluya formas de participación en la formulación de decisiones e implementación de acciones, y la coordinación entre sociedad civil, sector privado y Estado en forma horizontal y vertical. Se reconoce que las iniciativas para crear estos mecanismos de gobernanza han sido pocas y fragmentadas, y sugiriendo una aproximación multiescalar, se postula que la creación de Comités Regionales de Cambio Climático, bajo el contexto de descentralización y del principio de subsidariedad, serían un impulso clave, complementado con organismos locales, tales como Comités Ambientales Comunales, Juntas de Vecinos y empresas, para elaborar planes y proyectos coordinados, coherentes a nivel territorial, actualizados periódicamente, y con seguimiento y financiamiento que sustente su implementación (Muñoz et al., 2019).

Chile ha elaborado el Plan de Acción Nacional de Cambio Climático (PANCC), que cuenta con dos versiones (PANCC I 2008-2012 y PANCC II 2017-2022). El primero aborda diferentes temáticas relacionadas con los problemas urbanos (transporte, contaminación del aire y agua, zonas costeras), pero sin profundizar las propuestas que consideran a las ciudades como unidades territoriales sistémicas e integradas. La segunda versión de este Plan, manteniendo su carácter sectorial, establece medidas generales de mitigación, adaptación y gobernanza que abarcan una significativa variedad de sugerencias relativas a movilidad, transporte, planificación del territorio, urbanización, edificación sustentable, infraestructura pública, uso de la energía y abastecimiento de agua y el fomento del uso de tecnologías limpias y renovables según acuerdos internacionales. El documento enfatiza la idea de que las ciudades son el motor esencial de cambio para que el buen funcionamiento de las actividades se vincule de manera transversal con las propuestas de Cambio Climático (Muñoz et al., 2019).

Por otro lado, en 2012 se presentó el primer "Plan de Acción Climática para la Región Metropolitana de Santiago", que, de acuerdo a Romero-Lankao et al. (2013), significó que la planificación para el Cambio Climático urbano en aislamiento de otras instituciones generara un falso sentido de capacidad de respuesta institucional, en circunstancias que las políticas que orientaban el crecimiento económico tenían prioridad sobre la protección ambiental y la reducción de riesgos. Ello implica enfrentar desafíos, tales como la fragmentación de los arreglos de gobernanza, asimetrías en acceso a la información y tomas de decisiones tecnocráticas desde arriba hacia abajo. Para los autores, el Cambio Climático era y es aún un tema secundario comparado con otras prioridades del desarrollo, persistiendo una tensión entre las preocupaciones ambientales y las preferencias dadas al crecimiento urbano.

Como la totalidad de los componentes ambientales, el clima urbano se ha comodificado (Romero \& Vásquez, 2005) y, por ello, solo tienen acceso a las zonas de mayor calidad y confort climático quienes puedan pagar un alto precio por habitar en un lugar dentro de la ciudad que garantice bienes y servicios ecosistémicos que resultan indelegables, tales como respirar un aire de calidad, saludable y seguro. La mayoría de la población, debido a sus menores ingresos económicos, debe residir permanentemente en medio de una atmósfera contaminada o de "territorios de sacrificio climático" que registran temperaturas máximas y mínimas extremas, sequedad permanente, falta de vientos y brisas y elevadas concentraciones de contaminantes. Los sufrimientos climáticos, representados por olas e islas de calor y frío, no se distribuyen homogéneamente al interior de las ciudades. Más aún, la residencia en un área de adecuada calidad y seguridad climá- 
tica se ha tornado crecientemente un bien escaso, aumentando con ello su valor en el mercado inmobiliario, contribuyendo de esta forma a la injusticia y falta de equidad territorial que lamentablemente afecta a la casi totalidad de las ciudades chilenas.

Conocer y comprender la climatología urbana es, entonces, un factor esencial para planificar ciudades sostenibles. En general, las ciudades grandes y medianas de América Latina continúan creciendo a un ritmo muy rápido, cambiando las condiciones climáticas y generando incertidumbre sobre su comportamiento temporal y espacial futuro, lo que impide, entre otros factores, su consideración en los planes de desarrollo urbano (Gallardo et al., 2012; Romero, 2019). Los estudios iniciales del clima urbano solo diferenciaban entre los espacios rurales y urbanos (o entre centro y periferia de las ciudades), replicando modelos de análisis aplicables a países que planifican y controlan estrictamente el crecimiento y distribución de sus espacios urbanos, lo que no es el caso de las ciudades latinoamericanas. En estas, la falta de regulaciones y el poblamiento espontáneo han generado un complejo y fragmentado mosaico de numerosos patrones distintos de uso y ocupación de la tierra y, consecuentemente, creado diferentes Zonas Climáticas Locales (Stewart \& Oke, 2012), además de islas, islotes, corredores y puntos de calor y frío extremos.

La diferenciación socioespacial de las condiciones ambientales dentro de las ciudades impide cualquier generalización sobre su climatología urbana, como resultado de las condiciones locales que generan entornos complejos y distintos para cada vecindario. En la ciudad de São Paulo (Brasil), una de las urbes más grandes del mundo, un reciente estudio consideró en forma integrada condiciones y cambios de población, medio ambiente, delincuencia, vivienda, movilidad y expansión urbana, encontrando al menos ocho tipos de espacios urbanos locales fragmentados (Nery et al., 2019) a la escala de la llamada Capa Límite Urbana (Boundary Layer Climates, de Oke, 1978). En la escala de la capa atmosférica localizada bajo la altura máxima de las edificaciones (Canopy Layer, según Oke, 1978), la temperatura de la superficie medida in loco superó los $80^{\circ} \mathrm{C}$ en el techo de un automóvil oscuro y en el asfalto puede alcanzar $65^{\circ} \mathrm{C}$ en un caluroso día de verano, mientras la vegetación puede mitigar estos rangos extremos, creando condiciones climáticas más agradables (Mendes et al., 2019).

En Santiago de Chile, los proyectos inmobiliarios representan una de las principales inversiones económicas y, junto a las urgencias sociales, han reducido significativamente la comprensión y consideración de los vínculos entre sociedad y naturaleza, privatizando y comodificando los recursos, bienes y servicios ecosistémicos. Ello ha disuelto, consecuentemente, la noción de bien común aplicable al territorio, medio ambiente y clima de las ciudades y, por lo tanto, obstaculizado la implementación de políticas públicas destinadas a controlar la expansión urbana y asegurar el logro de objetivos ambientales explícitos tales como evitar los riesgos socionaturales, mitigar y adaptarse al Cambio Climático y conseguir mejores niveles de equidad territorial, justicia ambiental, calidad de vida y salud (Romero \& Vásquez, 2005; Romero et al., 2012; Inostroza et al., 2016; Vásquez et al., 2016; Barrera \& Henríquez, 2017). Como consecuencia, se han encontrado islas de calor urbano por encima de $5^{\circ} \mathrm{C}$ en el área más densamente construida del centro de la ciudad y en comunas ("conjunto de barrios") como Quilicura, ubicada al NW de la ciudad, donde alternan espacios industriales, residenciales de alta densidad y algunos remanentes de superficies agrícolas (Sarricolea Espinoza \& Martín-Vide, 2014), lo que resulta en una mayor demanda de energía (Nuruzzaman, 2015). 
El objetivo del presente trabajo ha sido analizar la evolución climático-ambiental de la urbanización de Santiago de Chile en un período de tiempo relativamente largo (2000 y 2019), con la finalidad de proporcionar antecedentes que permitan evaluar si el diseño y construcción de los espacios urbanos constituyen una contribución o, por el contrario, una oposición a los planes de lucha contra el Cambio Climático.

\section{Material y Métodos}

\section{Área de estudio}

Chile es un país con aproximadamente 18 millones de habitantes cuya capital, Santiago, es la ciudad más poblada, con más de cinco millones de habitantes, aunque la Región Metropolitana de Santiago supera los siete millones (INE, 2017). Se ubica en la parte central del país y, según la clasificación climática de Köppen-Geiger, el clima es de tipo mediterráneo (Csb), con verano cálido y seco, e invierno templado y lluvioso (Peel et al., 2007), donde la contaminación atmosférica por material particulado (MP10 y MP2,5) emitida principalmente por los vehículos, las industrias y el consumo de leña es un riesgo ambiental crítico (Romero et al., 2010).

Para comprender el proceso de Cambio Climático urbano causado por el crecimiento y densificación de Santiago, se llevaron a cabo dos análisis: el primero fue estudiar a escala de la Capa Límite Urbana la evolución de la temperatura de la superficie del suelo (TS) en un período de tiempo relativamente largo (2000 y 2019), mientras que el segundo, representativo de la escala de Canopia Urbana, consistió en una simulación microclimática para investigar cambios en el flujo del viento en un recorte urbano realizado en la comuna de Estación Central, sede de la instalación de los llamados "guetos verticales", caractrizados por conjuntos de edificios de gran altura que concentran sectores sociales específicos.

\section{Datos}

Para considerar la distribución espacial de la temperatura de la superficie del suelo en Santiago se utilizaron imágenes del satélite Landsat-7 (banda térmica 6), que fue lanzado por la NASA en abril de 1999, identificando áreas cálidas y frescas (con y sin vegetación). La metodología propuesta por Congedo (2014) se adoptó, a través del Semi-Automatic Classification Plugin (SCP) para el software QGIS versión 2, que convierte el valor del Digital Number (DN) en temperatura de superficie. Se compararon las imágenes del 27 de enero de 2000 y 31 de enero de 2019 , correspondientes a la estación de verano (Path: 233; Row: 083). Por lo tanto, las imágenes elegidas representan una de las más antiguas y una de las más recientes disponibles para el verano austral. En Santiago, el paso del Landsat-7 se realiza por la mañana, alrededor de las 10.30 hora local (UTC4), momento en el que las superficies comienzan a calentarse; de esta forma, las horas siguientes mostrarían diferencias aún mayores en las temperaturas superficiales, como el asfalto, en torno de las 12.00 o $13.00 \mathrm{hrs}$. La vegetación, por su parte, por cerrar sus estómas foliares para no perder agua frente a las altas temperaturas, alcanza sus mayores temperaturas al medio de la tarde (Mendes et al., 2019). 
Las imágenes de Landsat-7 han presentado ruido en sus bordes desde mayo de 2003 (Pires \& Ferreira Jr., 2015); sin embargo, la ciudad de Santiago se encuentra en el medio de la escena 233083 y no se ha visto comprometida, por lo que dispone de suficiente información útil, ya que su banda térmica tiene una resolución espacial de $60 \mathrm{~m}$, mientras que el Landsat-8, con una resolución espacial de $100 \mathrm{~m}$, representa menores detalles. Además, Landsat-8 se lanzó solo en 2013 (INPE, 2019), lo que hace imposible comparar los veinte años de cambio aquí propuestos. Con respecto a la elección de la imagen, se consideraron dos requisitos: (i) la imagen (ciudad) no debe estar cubierta por nubes, lo que dificulta la identificación remota del objeto y (ii) evitar épocas del año entre mediados de otoño e invierno, porque la presencia de árboles caducifolios podría sesgar los datos.

Para la simulación del microclima se utilizó el modelo ENVI-met versión 3, capaz de realizar interacciones entre la superficie terrestre, las plantas y el aire. Esta versión gratuita requiere dos archivos de entrada: (i) extensión .in (Figura $\mathrm{N}^{\circ} 1$ ), que corresponde al modelado del área, ubicando y caracterizando los diferentes elementos urbanos; consiste en la inserción de una imagen aérea (como de Google Earth, guardada en formato .bmp) para ayudar al operador con la localización de edificios y sus alturas (esto a través de Google Street View y verificación in loco - considerando cada piso de $3 \mathrm{~m}$ de altura), tipos de vegetación con su densidad de dosel, tipos de suelo y fuentes contaminantes; (ii) archivo de configuración de extensión .cf, (Figura №2), que contiene las variables climáticas de entrada, como dirección y velocidad del viento, temperatura potencial, humedad relativa y humedad específica. Se eligió una sección en la comuna de Estación Central (vecina del Centro), que ha mostrado muy rápido crecimiento urbano y verticalización incontrolada, lo que representa un potencial problema para el medio ambiente de la ciudad.

Figura $\mathrm{N}^{0} 1$.

Área modelada en el software ENVI-met, con asignación y caracterización de edificios (gris), vegetación (verde) y suelo (blanco), y su imagen aérea

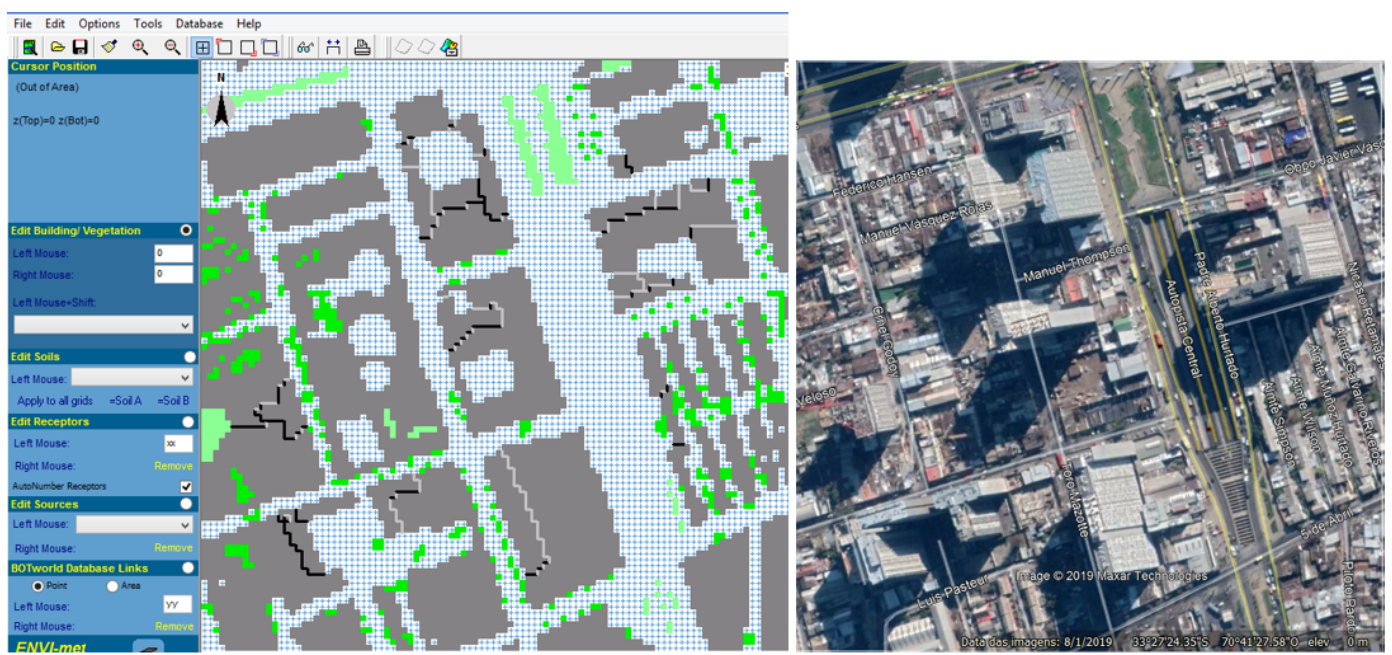

Fuente: Elaboración propia y Google Earth, respectivamente 
Figura $\mathrm{N}^{\circ} 2$.

Datos de microclima utilizados en la simulación

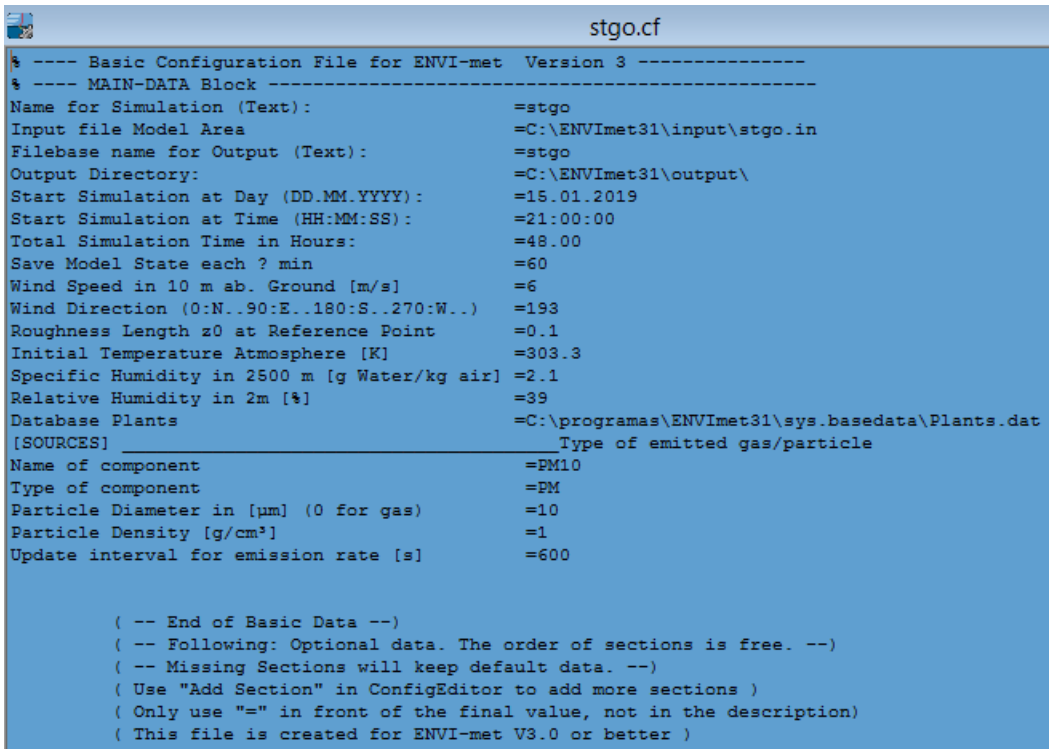

Fuente: Estación Meteorológica del Aeropuerto de Pudahuel (855740) y Departamento de Ciencia Atmosférica de la Universidad de Wyoming, para promedios de enero/2019, a las $21.00 \mathrm{hrs} \mathrm{local}$

En esta área verticalizada de la ciudad hay edificios de casi $100 \mathrm{~m}$ de altura, con 30 pisos construidos. Estos edificios alternan en el espacio urbano con casas antiguas, en su mayoría de un solo piso, y que alcanzan aproximadamente $5 \mathrm{~m}$ de altura en promedio. Las especies arbóreas más abundantes en el sitio fueron acacio (Robinia pseudoacacia), liquidambar (Liquidambar styraciflua) y ciruelo (Prunus cerasifera), que también corresponden a las más abundantes en la ciudad de Santiago (Hernández \& Villaseñor, 2018). Por lo tanto, de la base de datos disponible en ENVI-met, se utilizaron los códigos de vegetación: ds (árbol de $10 \mathrm{~m}$ de altura y copa distinta), $\mathrm{H} 2$ (arbusto denso de $6 \mathrm{~m}$ de altura), h (arbusto denso de $2 \mathrm{~m}$ altura) y g (pasto). La metodología de simulación adoptada fue propuesta por Mendes (2014). El corte espacial fue de $500 \times 500 \mathrm{~m}$ (25 hectáreas). Para este modelo, se utilizó una cuadrícula ( $X ; Y ; Z)$ de $100 \times 100 \times 20$, por lo tanto, cada cuadrícula $d x=d y=5,0 m$ y dz $=10,0 \mathrm{~m}$, además de otras 5 cuadrículas de borde sugeridas por el modelo para evitar interferencias con los resultados. El procesamiento se realizó en una máquina virtual Intel ${ }^{\circledR}$ Xeon E7-2870 a $2,40 \mathrm{GHz}$ (8 procesadores en clúster) con $32 \mathrm{~GB}$ de RAM, lo que requiere cinco días de simulación ininterrumpidos, descartando los resultados del primer día simulado para conseguir la estabilización del modelo ENVI-met.

\section{Resultados y Discusión}

Toda la Región Metropolitana de Santiago y las ciudades chilenas han mostrado un crecimiento espacial muy rápido en las últimas décadas, reemplazando las áreas naturales y agrícolas por superficies urbanizadas, generando islas de calor y cambios en la humedad y ventilación. Debido a sus condiciones topográficas en medio de una cuenca rodeada de montañas, como la Cordillera de los Andes al oriente y la Cordillera de la Costa del Pacífico Sur al poniente, la ventilación en Santiago 
está aún más comprometida, especialmente con respecto a los contaminantes, los cuales terminan concentrándose en la ciudad, dificultando su dispersión (Romero et al., 2010). La estabilidad atmosférica causada por las inversiones térmicas (aumento de temperatura con la altura) de subsidencia (descenso de masas de aire desde la alta atmósfera propia de los anticiclones o centros de alta presión), y de radiación (enfriamiento de la superficie del suelo en las estaciones de otoño e invierno que transfiere las bajas temperaturas a las capas de aire cercanas) termina intensificándose por la escasez de precipitaciones, del orden de $342 \mathrm{~mm} /$ año (Meteochile, 2019), que pueden caer en menos de diez días en un año seco y en cerca de cuarenta días en un año lluvioso, casi exclusivamente en los meses de mayo, junio, julio y agosto. La escasez e irregularidad de las lluvias y el escaso número de perturbaciones atmosféricas que acompañan su paso no ayudan a limpiar el aire, favoreciendo el depósito de los contaminantes principalmente en los sectores más deprimidos topográficamente, localizados al poniente de la cuenca y en los barrios de la ciudad que también registran las mayores islas y archipiélagos de calor. Por otro lado, con la poca lluvia, no hay tantos problemas con la caída de árboles urbanos, en comparación con las ciudades de clima tropical, como Brasil, en el que el suelo con mucha agua puede comprometer la estabilidad de estos, causando daños (Mendes et al., 2016). De esta manera, las áreas verdes, como arbolado urbano, plazas y bosques, aparecen como una alternativa para mitigar estos problemas ambientales (He et al., 2019).

La ciudad de Santiago tiene actualmente 32 comunas urbanas bajo administración municipal, que albergan al $78 \%$ de la población regional (Santiago, 2019). Fue posible comparar la evolución de las temperaturas superficiales durante un período de casi 20 años, es decir, entre los años 2000 (Figura $\mathrm{N}^{\circ} 3$ ) y 2019 (Figura $\mathrm{N}^{\circ} 4$ ), así como determinar sus diferencias (Figura N5), identificando las áreas de mayor temperatura (Figura $\mathrm{N}^{\circ} 6$ ). Las clases de temperatura fueron estandarizadas a la misma escala para la preparación de mapas, lo que permitió conocer sus diferencias.

Figura $\mathrm{N}^{\circ} 3$.

Temperatura superficial en Santiago, en enero del año 2000

$-70.8$

$-70.5$

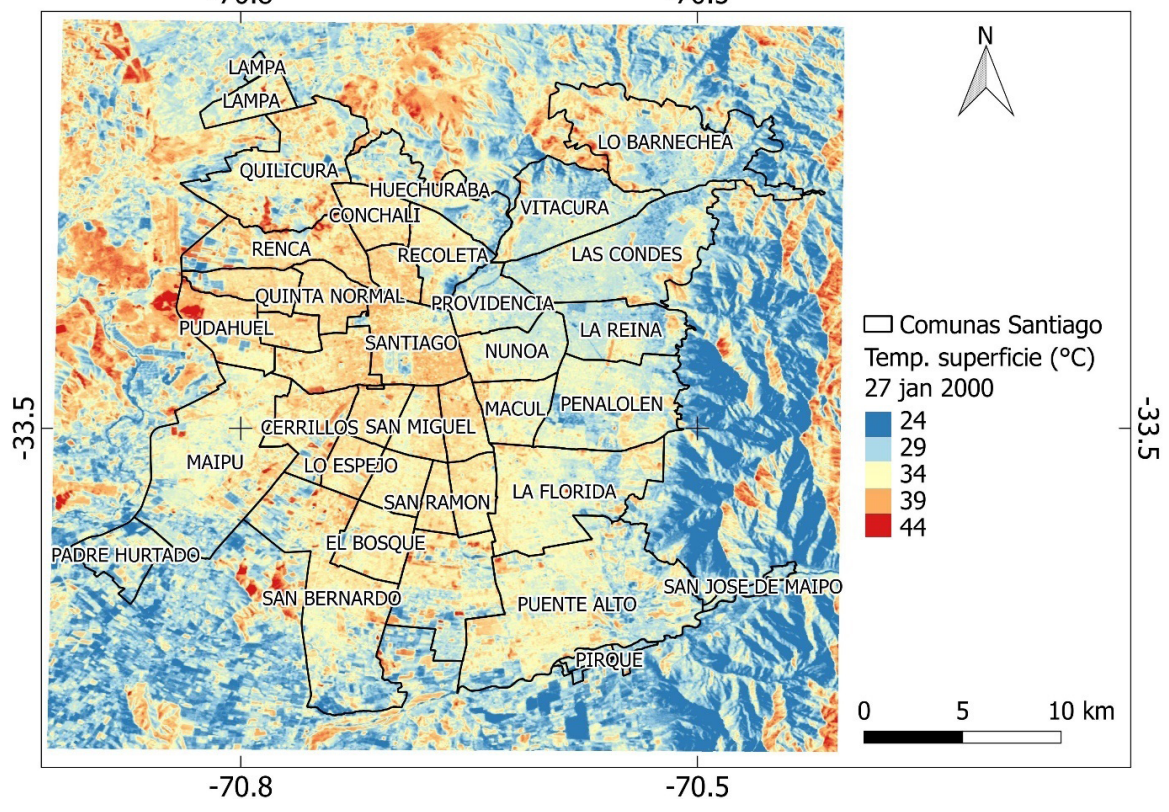

Fuente: Elaboración propia, desde la imagen térmica Landsat-7 
Figura $\mathrm{N}^{\circ} 4$.

Temperatura superficial en Santiago, en enero del año 2019

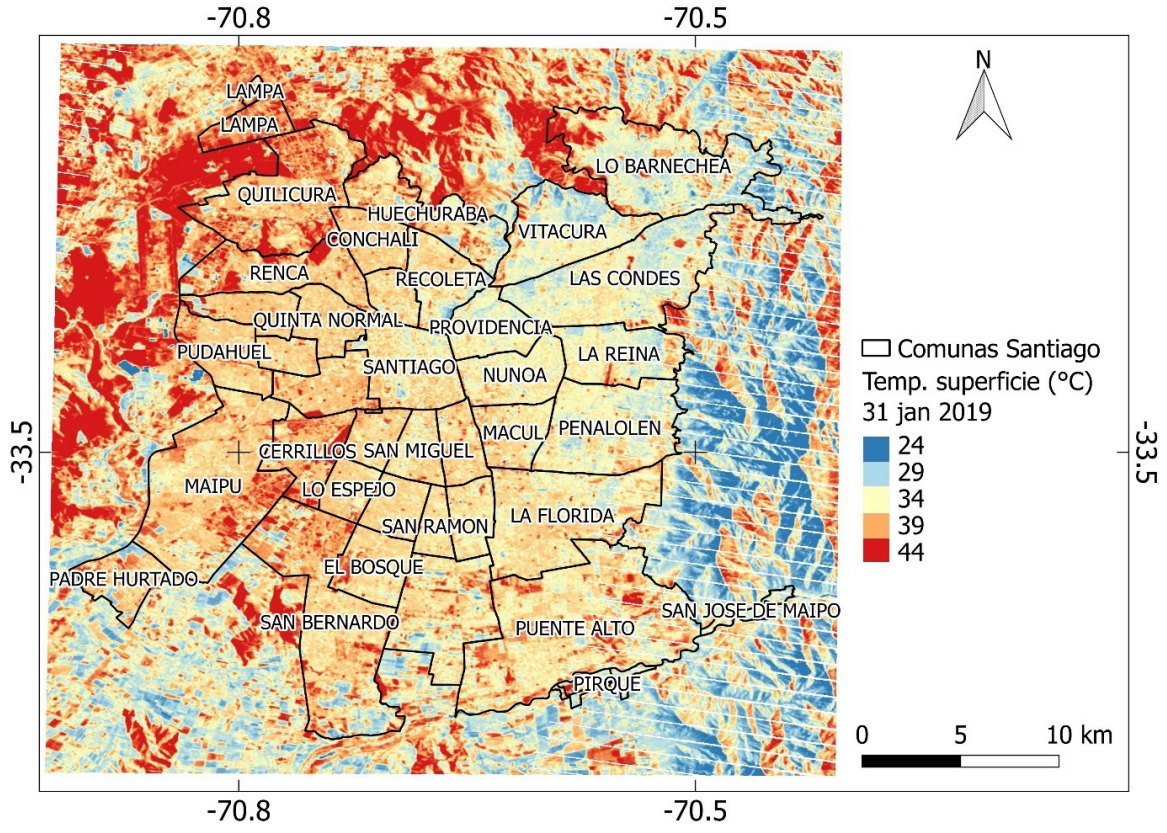

Fuente: Elaboración propia, desde la imagen térmica Landsat-7

Figura $\mathrm{N}^{\circ} 5$.

Evolución comunal de la temperatura de la superficie en Santiago, entre los años 2019 y 2000 $-70.8$ $-70.5$

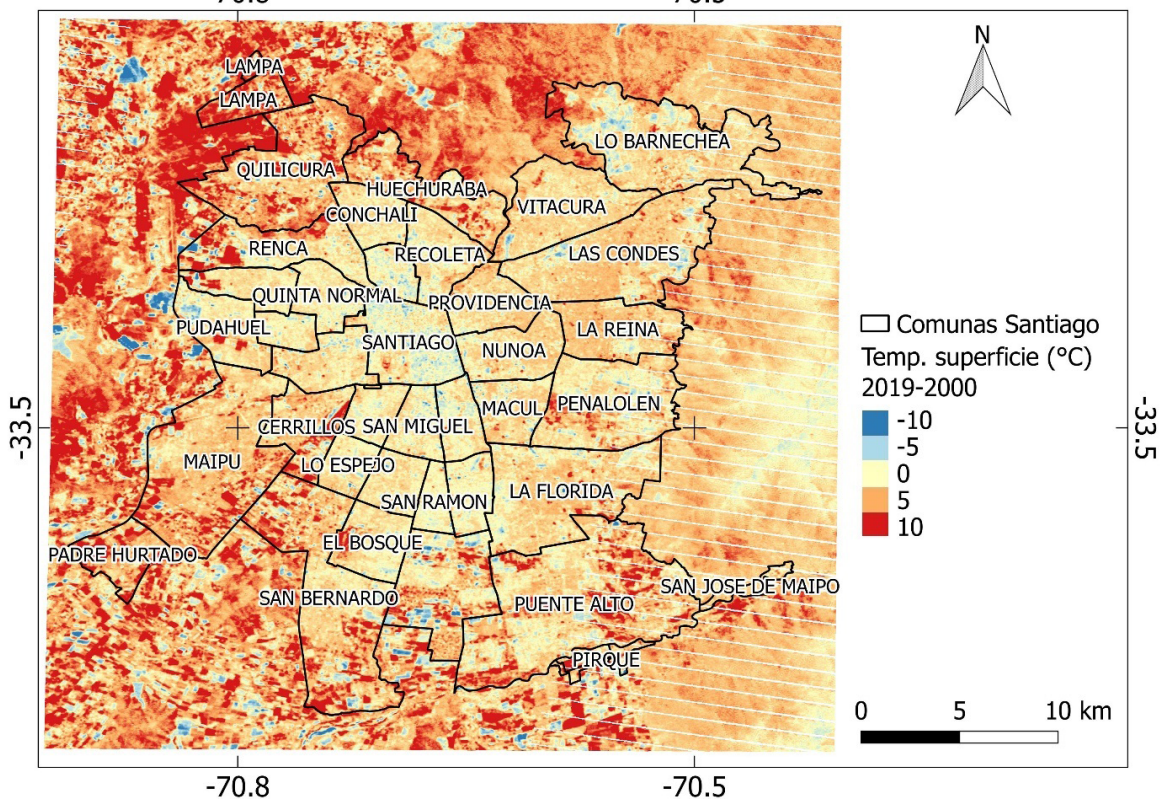

Fuente: Elaboración propia, desde imágenes térmicas Landsat-7 
Figura $\mathrm{N}^{\circ} 6$.

Análisis binario (sí - rojo / no - blanco) de las áreas que aumentaron su temperatura entre los años 2000 y 2019

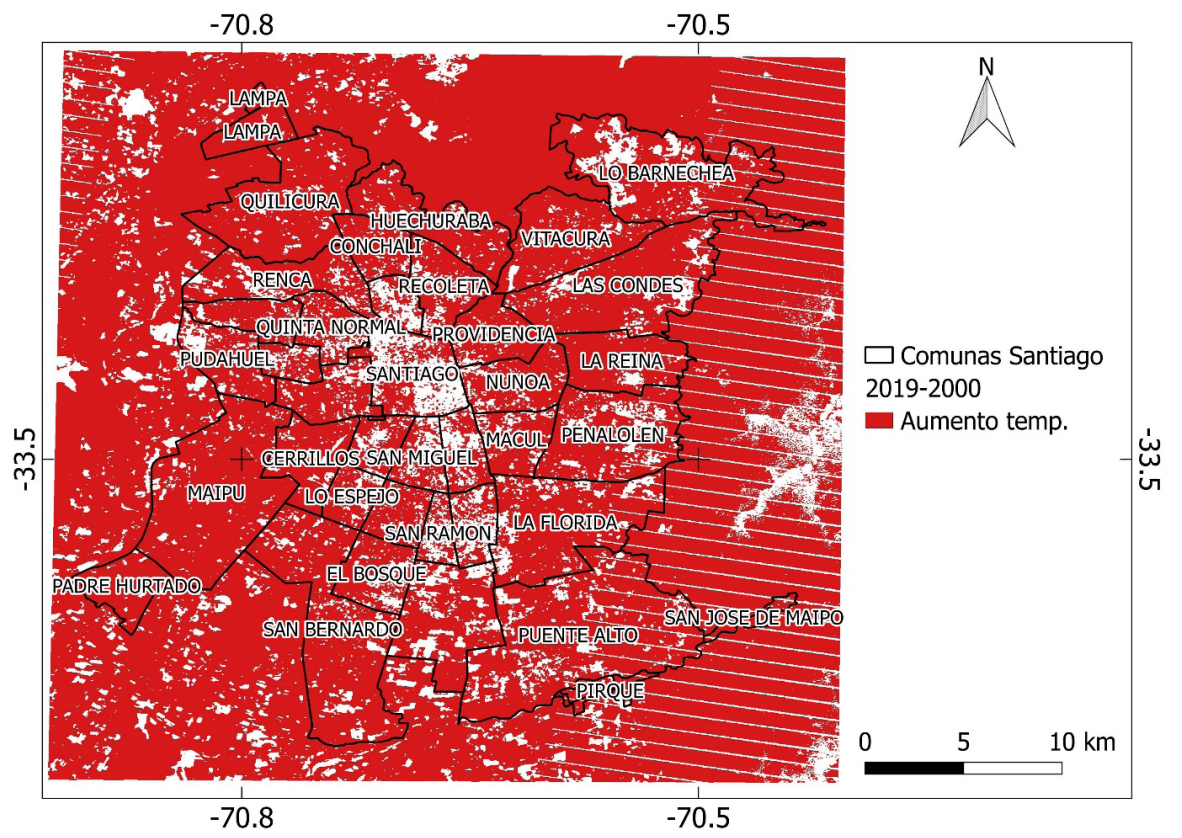

Fuente: Elaboración propia, desde imágenes térmicas Landsat-7

En general, se puede afirmar que Santiago de Chile aumentó considerablemente sus temperaturas superficiales (TS), sustituyendo usos y coberturas naturales por zonas impermeabilizadas y densificando sus superficies construidas (Figura $\mathrm{N}^{\circ} 6$ ). En las áreas más frías ubicadas al interior de la ciudad, que cuentan con grandes áreas cubiertas de vegetación, las TS variaron entre 25 y $30^{\circ} \mathrm{C}$, mientras que en las más cálidas, los suelos expuestos registraron hasta $50^{\circ} \mathrm{C}$. Es decir, existe una diferencia de hasta $25^{\circ} \mathrm{C}$ en las temperaturas del suelo al interior del área urbana de Santiago. Además, como enero es un mes en que nunca se registran precipitaciones, la cantidad de agua en el suelo fue baja en ambos años analizados. La precipitación acumulada en los últimos tres meses anteriores a enero no superó los $5 \mathrm{~mm}$, según datos de la Estación Meteorológica del Aeropuerto de Pudahuel. Consecuentemente, el aumento de las temperaturas superficiales y su altísima variación al interior de la ciudad se deberían relacionar mayormente con los cambios introducidos por la urbanización, debido a la carencia de instrumentos de evaluación ambiental que consideren las transformaciones climáticas. Paradójicamente, ello ocurre simultáneamente con el incremento aparente de la preocupación social por el Cambio Climático y por la adhesión del país a los acuerdos internacionales destinados a conseguir la disminución de las temperaturas, la cual termina afectando la credibilidad de las instituciones y el escepticismo de la ciudadanía.

Las comunas ubicadas al oriente de la ciudad, como Vitacura, Las Condes y Lo Barnechea y la parte norte de Providencia, siguen siendo las más frescas (Figura N4), debido a que cuentan con más áreas verdes y son ventiladas por los flujos valle-montaña. Aún así también han aumentado sus temperaturas entre 2000 y 2019. Por el contrario, la comuna de Santiago Centro, que en 2000 fue una de las más cálidas, logró reducir sus temperaturas del suelo, aunque todavía 
registra valores entre $30^{\circ} \mathrm{C}$ y $40^{\circ} \mathrm{C}$ en los meses de pleno verano. También se observa que las comunas de Quilicura y Cerrillos, correspondientes a las porciones noroeste y suroeste del recorte (Figura $\mathrm{N}^{\circ}$ ), tuvieron un aumento considerable, por encima de $10^{\circ} \mathrm{C}$, alcanzando en 2019 TS de hasta $50^{\circ} \mathrm{C}$. Esto se justificaría por el cambio de suelos con vegetación a suelos desnudos o impermeabilizados (Figura $\mathrm{N}^{\circ} 7$ ), como Sousa y Ferreira (2012) lo verificaron en los cambios de usos y coberturas de suelo de vegetados a desnudos en el Bioma Cerrado brasileño. Complementariamente, se deben analizar cuidadosamente las áreas montañosas que, por su parte, presentan una alta heterogeneidad en los valores de TS debido a factores topográficos (elevación, exposición y pendiente), cobertura vegetal y radiación solar, entre otros, que pueden variar en más de $16^{\circ} \mathrm{C}$ $\mathrm{km}^{-1}$ entre las laderas de orientación de solana y umbría (He et al., 2019). Este hecho no puede atribuirse exclusivamente a la urbanización del piedemonte andino, como ha ocurrido principalmente en la parte occidental de la ciudad (Cordillera de la Costa), y también más puntualmente en Cerro Calán (cerro localizado en la comuna de Las Condes al oriente de la ciudad) y en el antiguo Aeropuerto de Cerrillos (Figura $\mathrm{N}^{\circ} 8$ ), revelando que cada caso debe analizarse por separado. El impacto ambiental de estos cambios se encuentra en Romero y Vásquez (2005) y Romero (2019).

Figura $\mathrm{N}^{\circ} 7$.

Cambios en los usos y coberturas de suelos y en las temperaturas superficiales en la comuna de Quilicura, entre los meses de enero de los años 2000 y 2019. Nótese los efectos de la sustitución de áreas agrícolas por suelos desnudos

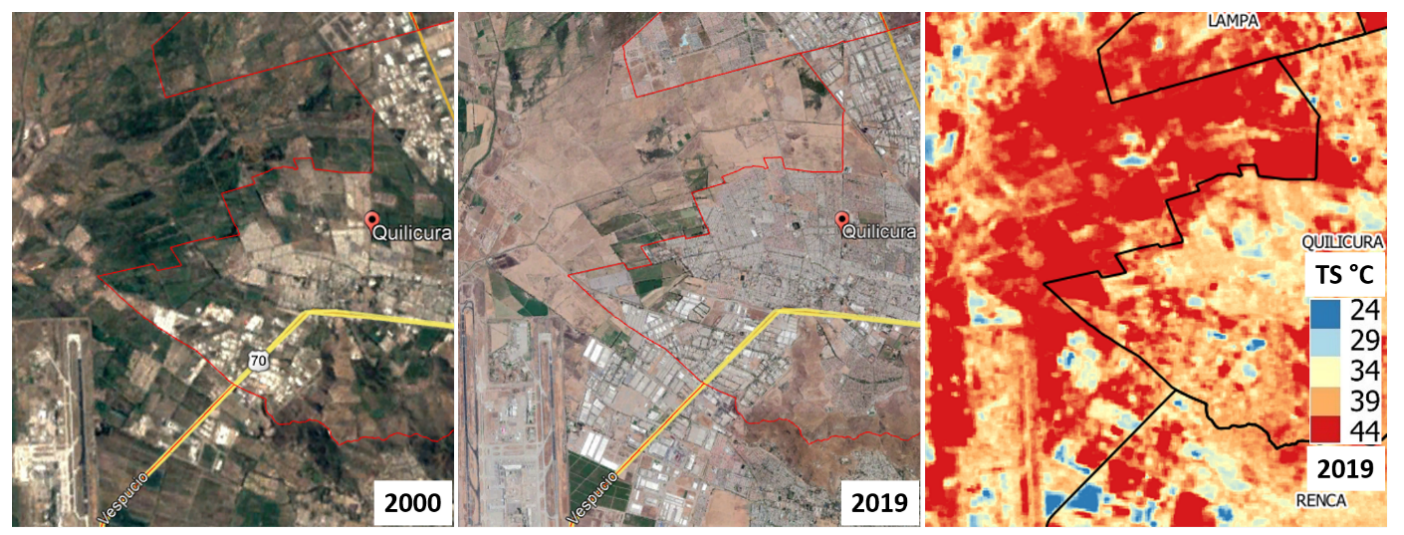

Fuente: Google Earth (izquierda y centro) y elaboración propia (derecha)

A nivel del follaje o canopia urbana, la urbanización cuya planificación no tiene en cuenta los impactos ambientales, aumenta continuamente la temperatura y también puede dificultar la ventilación, un factor extremadamente importante en el equilibrio climático de las ciudades y especialmente en el control de las islas y olas de calor y de la contaminación del aire. En la comuna de Estación Central, vecina a Santiago Centro, la verticalización y densificación de las construcciones llevadas a cabo durante los últimos años explican la presencia actual de los llamados "guetos verticales", un grupo socialmente diferenciado de más de dos mil departamentos distribuidos en edificios de más de 30 pisos, donde residen principalmente inmigrantes y grupos sociales de ingresos medio-bajos. En este caso, el obsoleto Plan Regulador Comunal de 1983 ha sido utilizado por el sector inmobiliario para instalar proyectos de altura desproporcionada (Miranda, 2017), aprovechando su localización en áreas de alta disponibilidad de transporte público, 
Figura $\mathrm{N}^{\circ} 8$.

Cambios en los usos y coberturas de suelos y en las temperaturas superficiales en el antiguo aeropuerto de Cerrillos, entre los meses de enero de los años 2000 y 2019. Nótese la sustitución de áreas verdes por suelos desnudos

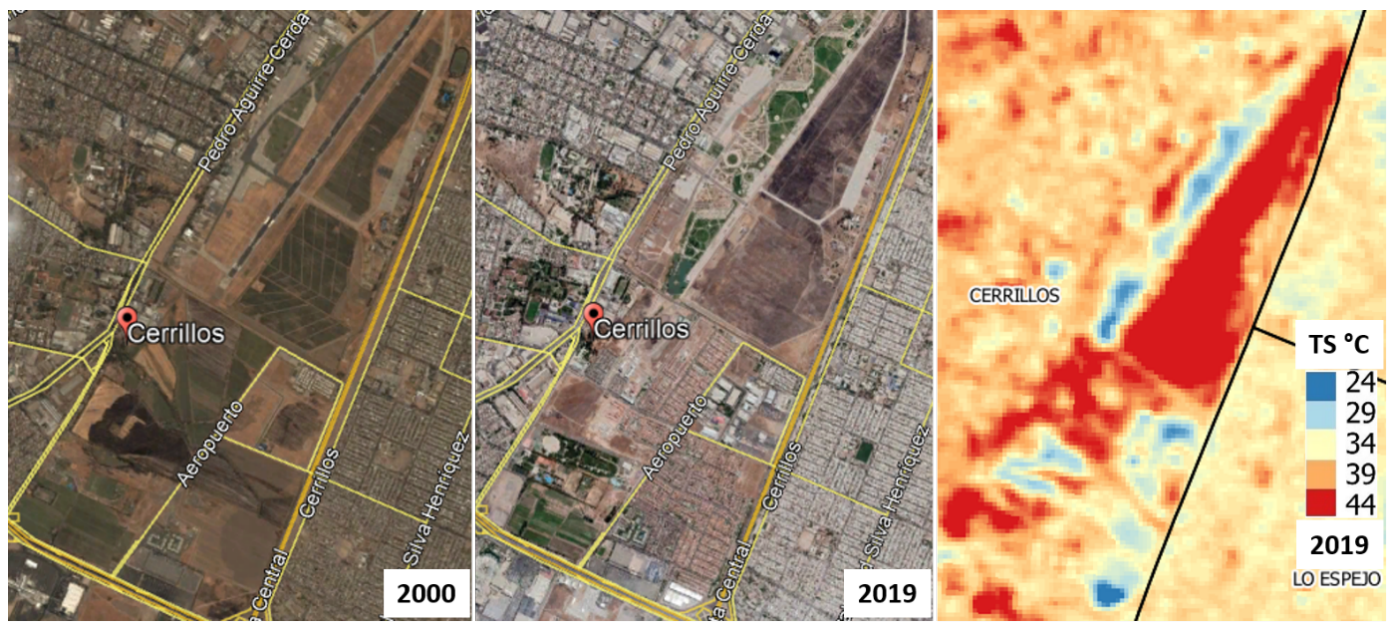

Fuente: Google Earth (izquierda y centro) y elaboración propia (derecha)

tales como metro y tren (Estación Central) y autobuses urbanos, interurbanos e internacionales (Terminal Sur), respondiendo a las demandas del mercado, sin realizar evaluación ambiental alguna. La altísima densidad demográfica y construida constituyen, en este caso, una fuente muy relevante de modificación de los climas urbanos previamente existentes debido a que las fachadas acumulan y reflejan la radiación solar entre las edificaciones, generando islotes y corredores de calor al mismo tiempo que eliminan las islas frías (jardines, parques y patios urbanos). Ello aumenta las concentraciones de contaminantes atmosféricos causadas por fuentes fijas y móviles y altera la topografía de los barrios, reemplazando las habitaciones unifamiliares de baja altura y con presencia de patios, por "cañones urbanos", formas que se reconocen cuando la altura de las edificaciones duplica a lo menos el ancho de calles y avenidas (Oke, 1978).

La simulación CFD (dinámica computacional de fluidos, en este caso el viento local), mostró que el diseño urbano actual en la comuna de Estación Central puede cambiar la dirección del viento original predominante del tercer cuadrante ( $193^{\circ}$ o viento sur en enero) en más de $60^{\circ}$ ( $\mathrm{Fi}$ gura $\mathrm{N}^{\circ} 9$ ). Los estudios que han investigado los efectos de la reducción y encauzamiento de los vientos sobre la dispersión de contaminantes, como el realizado por Aristodemou et al. (2018), en Londres (UK), demuestran la necesidad de realizar cuidadosas evaluaciones ambientales tanto en el diseño como en la planificación de estas nuevas formas urbanas. Ello es especialmente válido para el caso de Santiago, donde la acumulación de calor y la contaminación atmosférica constituyen problemas ambientales crecientes. En el caso de Londres, los rascacielos de más de 150 $\mathrm{m}$ de altura han afectado los flujos de aire y los patrones de dispersión de contaminantes y calor, generando las llamadas "zonas muertas".

Como en la investigación mencionada anteriormente, este trabajo también encontró este tipo de "zonas muertas" en la comuna de Estación Central, en las cuales la velocidad del viento a una 
altura de $10 \mathrm{~m}$ y a sotavento (área protegida de los vientos predominantes) de los edificios, era muy baja, menos de $1 \mathrm{~m} / \mathrm{s}$ (Figura $\mathrm{N}^{\circ} 10$ ). Los mapas elaborados correspondieron a las $15.00 \mathrm{hrs,}$ que fue el momento más caluroso del día, cuando las temperaturas simuladas del aire alcanzaron los $37^{\circ} \mathrm{C}$, muy cercanas al valor real de $36^{\circ} \mathrm{C}$ encontrado por Smith y Romero (2016), para un día de verano en esta zona urbana. Las estimaciones de ventilación también se ejecutaron a $2 \mathrm{~m}$ de altura, debido a que se trata tanto del ambiente que acompaña a los peatones como a la circulación de automóviles, que lo hacen en una gran cantidad en la Autopista Central y Avenida Libertador General Bernardo O'Higgins (Ilamada paradojalmente "Alameda").

Figura $\mathrm{N}^{\circ} 9$.

Cambios superiores a $60^{\circ}$ en la dirección del viento predominante del sur $\left(193^{\circ}\right)$ y su relación espacial con los edificios (en negro) en la comuna de Estación Central

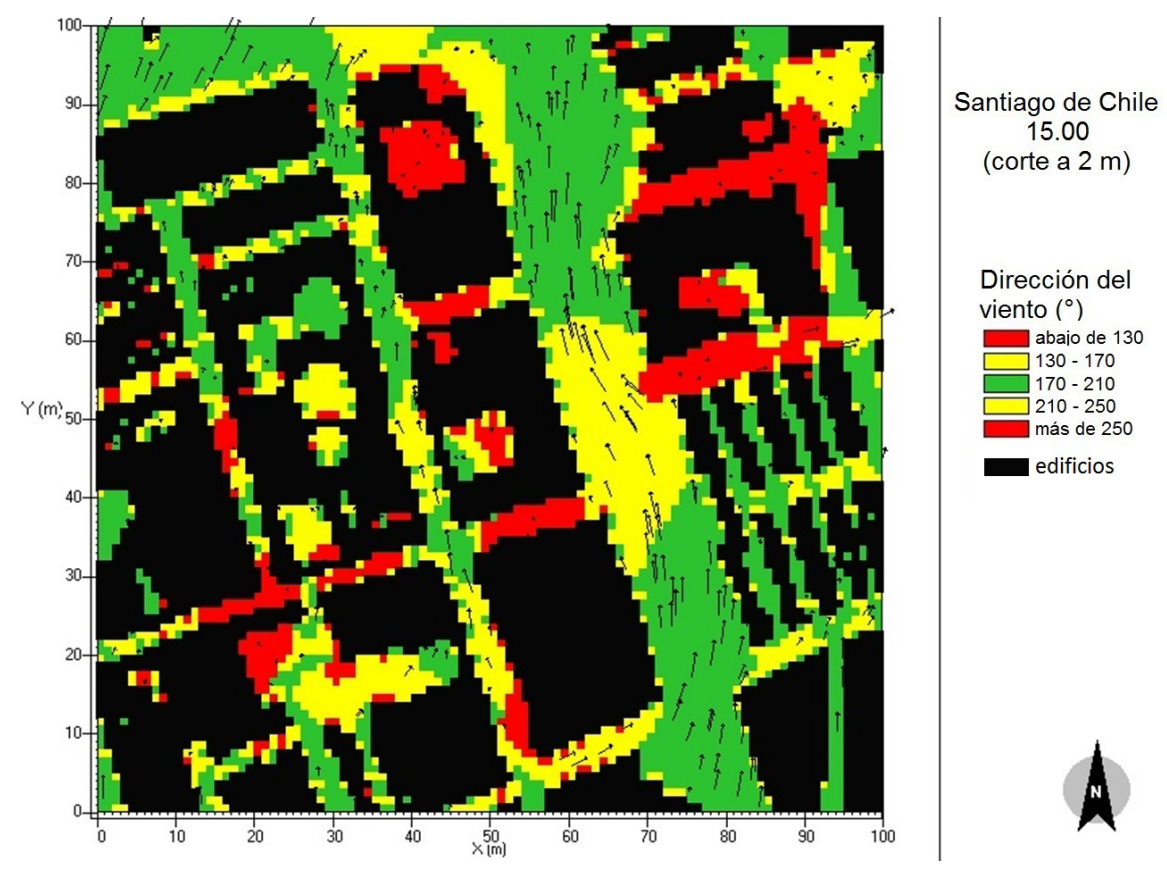

Fuente: Elaboración propia

Para la totalidad de los problemas ambientales mencionados, la forestación se convierte en un elemento esencial para el mejoramiento de los climas urbanos: consume calor en el proceso de evapotranspiración y proporciona sombra (que en el caso de Santiago es una forma muy relevante de mitigar los efectos de la temperatura) y humidifica la atmósfera, controlando los valores extremos; ayuda a la adsorción de contaminantes en sus hojas y troncos (Burden, 2006) y recicla contaminantes como el $\mathrm{CO}_{2}$ transformándolo en oxígeno. En el caso de la vegetación nativa, estas transformaciones son únicas en comparación con los árboles exóticos que producen contaminantes (Préndez et al., 2019); oferta refugios a la biodiversidad y brinda confortabilidad climática y espacios de alta valoración para el bienestar y salud humana.

Dado el deterioro climático analizado en ese trabajo, la pérdida de bosques, matorrales, humedales y superficies agrícolas y forestales, como consecuencia de la urbanización de la ciudad de 
Figura $\mathrm{N}^{\circ} 10$.

Cambios espaciales en la velocidad inicial de un viento de $6 \mathrm{~m} / \mathrm{s}$, relacionados con edificios de más de $10 \mathrm{~m}$ de altura (en negro) en la comuna de Estación Central
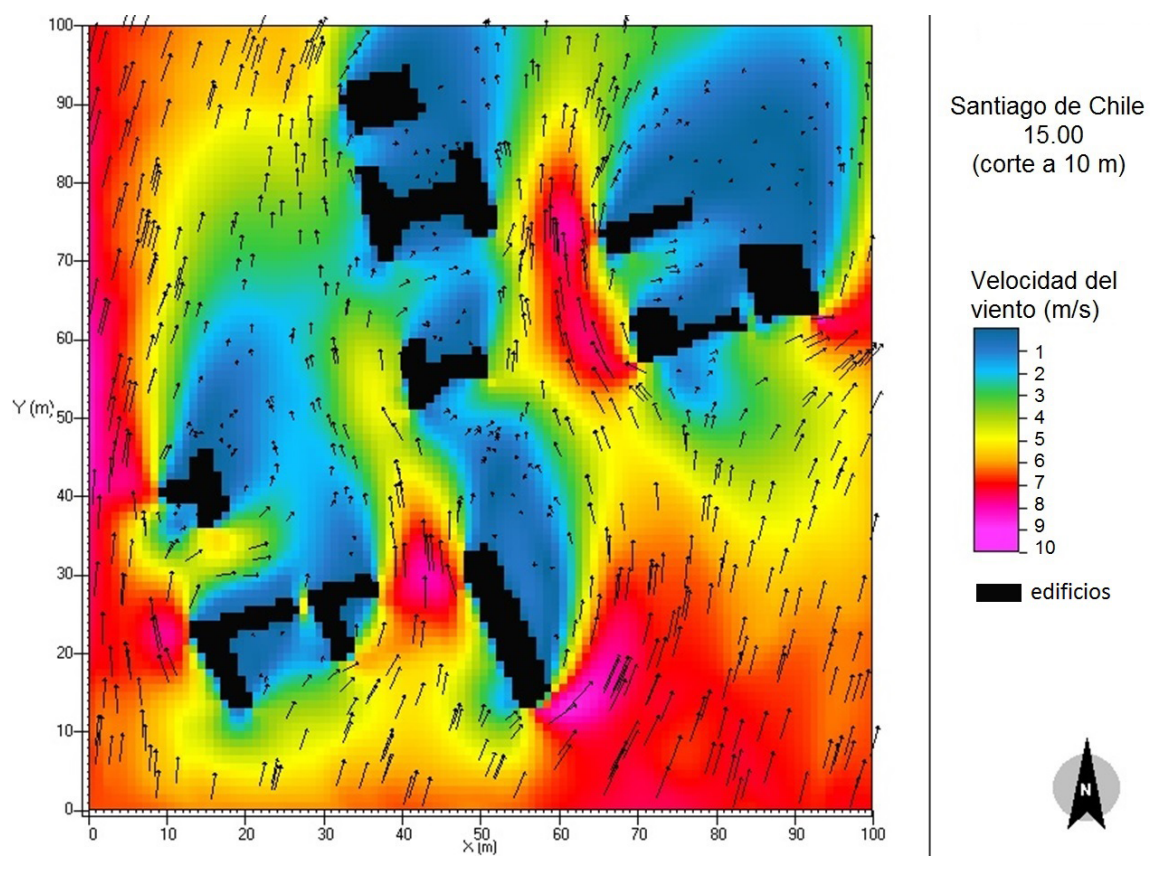

Fuente: Elaboración propia

Santiago, causa un daño ambiental significativo que acompaña a la transformación cotidiana de cada una de las hectáreas naturales por urbanizadas. El control y reducción de este daño y, por el contrario, la propuesta de una ciudad inmersa en una matriz natural, no ha formado parte de los principios de la planificación y gestión urbana en Chile y no se compadece con los compromisos adquiridos internacionalmente relativos a la mitigación y adaptación ante el Cambio Climático.

Algunas especies recomendadas para el arbolado urbano son peumos (Cryptocaria alba), quiIlayes (Quillaja saponaria) y canelos (Drimys winteri), especies perennes (siempre verdes), nativas de Chile, que tienen hojas relativamente pequeñas y son resistentes a la escasez de agua, haciendo que sus superficies sean más rígidas. Estas características son interesantes en la medida que son funcionales ante los cambios estacionales: en verano, proporcionan sombra, mientras que en invierno pueden ayudar en la purificación del aire, adhiriendo contaminantes dispersos en el aire en sus superficies foliares (Préndez et al., 2019). Sin embargo, se deben evitar los monocultivos, porque pueden comprometer la diversidad genética, dejando el arbolado urbano susceptible a las plagas, como la enfermedad del olmo holandés, que ocurrió por accidente en el este de los Estados Unidos a mediados del siglo XX, devastando millones de árboles (Sadava et al., 2009).

El urbanismo y la geografía física deberían estar más correlacionados al planificar las ciudades. Las adversas transformaciones climáticas acá analizadas tienen que ver con los objetivos y propósitos del desarrollo urbano en su conjunto y no solo con medidas de mitigación y adaptación al Cambio Climático. Si bien los incrementos de temperatura, disminución de la humedad 
atmosférica y eliminación o decrecimiento de la ventilación son los resultados evidenciados por los cambios de coberturas y usos del suelo, de naturales a urbanizados, dichas transformaciones se relacionan, a su vez, con las políticas y planes territoriales y de desarrollo de las ciudades, e incluyen los sectores de transporte, vivienda, educación, salud, áreas verdes y la infraestructura urbana en su conjunto. Las regulaciones espaciales, territoriales y ambientales que se deben introducir para asegurar la sustentabilidad climática urbana, el bienestar y salud de la sociedad pueden contrariar los intentos por asignar al mercado la distribución de los bienes y servicios ecosistémicos en la ciudad. Recientemente, el 18 de octubre de 2019, ocurrió el llamado "estallido social", un relevante hecho histórico de gran impacto global, en el que la sociedad chilena protestó contra las políticas y el modelo seguido para desarrollar el país y sus ciudades, donde residen nueve de cada diez habitantes, mostrando su indignación ante la situación actual. El clima urbano requiere ser recomunalizado, es decir, recuperar su condición de bien libre, colectivo y componente fundamental de un medio ambiente de calidad equitativamente distribuido.

Los cambios en los climas urbanos de Santiago de Chile son una demostración del dinamismo adquirido por las transformaciones del medio ambiente en un país de absoluto predominio de la población urbana que encuentra en la ciudad su verdadero nicho ecológico. La sociedad exige consistencia en los planes y medidas adoptadas y especialmente equidad e igualdad de oportunidades en las condiciones de habitabilidad de las ciudades. El clima y el aire deben dejar de ser bienes y servicios comodificados cuyo acceso depende de la capacidad adquisitiva de los compradores de inmuebles para recuperar sus características de bien común, como sucede con los bienes y servicios públicos que debiesen ofrecer las ciudades a la totalidad de sus habitantes. El estudio de caso realizado en la comuna de Estación Central muestra profundos errores e insuficiencias en la planificación y gestión ambiental de tales territorios, generando una evidente desproporción en el diseño urbano, con edificios de casi $100 \mathrm{~m}$ de altura, cuyas paredes acumulan una gran cantidad de calor, y que se localizan con orientación perpendicular a los vientos predominantes del sur y suroeste, lo que dificulta la moderación de las temperaturas y la dispersión de los contaminantes atmosféricos, creando cañones urbanos y efectos adversos sobre la calidad de vida de sus habitantes. Una simple consideración de esto haría recomendable no insistir en este tipo de urbanización en esa ni en ninguna otra comuna del país, o en caso de ser necesario, preferir posiciones más adecuadas de los edificios de altura, que alternen con avenidas anchas y parques urbanos, y que faciliten la ventilación, al ser paralelos y no perpendiculares a las direcciones predominantes del viento.

\section{Conclusiones}

La comparación de las imágenes satelitales de los años 2000 y 2019 permitió verificar un aumento de la temperatura de la superficie de los suelos en la mayor parte de la ciudad de Santiago, especialmente en aquellos terrenos desnudos y bajo alta insolación, que han llegado a registrar cerca de $50^{\circ} \mathrm{C}$. Un trabajo posterior deberá identificar el porcentaje de calor que es transferido a la atmósfera y desplazado a otros lugares por medio de vientos y brisas que justamente compensan las diferencias de temperaturas. Las comunas ubicadas al noreste (Vitacura, Las Condes, Lo Barnechea y Providencia) continúan siendo las más frescas, aunque también han aumentado sus temperaturas. Por otro lado, la comuna de Santiago Centro fue la que más logró controlar los cambios de temperatura, debiéndose también identificar en un trabajo posterior la forma de conseguirlo. 
Es evidente a través del incremento de las temperaturas superficiales y de los cambios en la dirección y velocidad de los vientos que la urbanización de la ciudad no ha estado contribuyendo a las expectativas de mitigar y adaptarse al Cambio Climático, a pesar de la preparación de diversos proyectos de investigación, políticas y planes nacionales y urbanos, generales y sectoriales, así como de una supuesta adhesión a acuerdos y estrategias internacionales. Por el contrario, es notable la generación de un ambiente cada vez más árido y el predominio de las olas e islas de calor, al mismo tiempo que se eliminan las islas y archipiélagos de frío y los vientos refrescantes y depuradores de la calidad del aire. Parece haber llegado el momento para que la climatología urbana sea considerada adecuadamente en los planes de ordenamiento territorial a escala urbana, superando una ausencia que se observa no solo en el caso de Santiago, sino que también en la casi totalidad de las ciudades grandes y medianas del país y del resto de Latinoamérica.

\section{Agradecimientos}

Este trabajo se llevó a cabo con el apoyo de Coordenação de Aperfeiçoamento de Pessoal de Nível Superior - Brasil (CAPES) - Código de Financiamiento 001, y Santander.

\section{Referencias}

ARISTODEMOU, E.; BOGANEGRA, L.M.; MOTTET, L.; PAVLIDIS, D.; CONSTANTINOU, A.; PAIN, C.; ROBINS, A. \& APSIMON, H. How tall buildings affect turbulent air flows and dispersion of pollution within a neighbourhood. Environmental pollution, 2018, vol. 233, p. 782-796.

BARRERA, F. \& HENRÍQUEZ, C. Vegetation cover change in growing urban agglomerations in Chile. Ecological Indicators, 2017, vol. 81, p. 265-273.

BARTON, J. Adaptación al cambio climático en la planificación de ciudades-regiones. Revista Geografía Norte Grande, 2009, № 43, p. 5-30.

BURDEN, D. Urban Street Trees: 22 Benefits Specific Applications. Orlando: Glatting Jackson and Walkable Communities Inc., 2006.

CONGEDO, L. Semi-Automatic Classification Plugin. User Manual. 2014.

DIRECCIÓN METEOROLÓGICA DE CHILE (Meteochile). Informe de Precipitaciones. 2019. Disponible en Internet: http://www.meteochile.gob.cl/PortalDMC-web/climatologia/inicio_climatologia/ informe_precipitaciones.xhtml. Acceso en: 27 dic. 2019.

GALLARDO, L.; ESCRIBANO, J.; DAWIDOWSKI, L.; ROJAS, N.; ANDRADE, M.F. \& OSSES, M. Evaluation of vehicle emission inventories for carbon monoxide and nitrogen oxides for Bogotá, Buenos Aires, Santiago, and São Paulo. Atmospheric Environment, 2012, vol. 47, p. 12-19. 
HE, J; ZHAO, W.; LI, A.; WEN, F. \& YU, D. The impact of the terrain effect on land surface temperature variation based on Landsat- 8 observations in mountainous areas. International Journal of Remote Sensing, 2019, vol. 40, N 5-6, p. 1808-1827.

HERNÁNDEZ, H.J. \& VILLASEÑOR, N.R. Twelve-year change in tree diversity and spatial segregation in the Mediterranean city of Santiago, Chile. Urban Forestry \& Urban Greening, 2018, vol. 29, p. 10-18.

INOSTROZA, L.; PALME, M. \& BARRERA, F. A heat vulnerability index: spatial patterns of exposure, sensitivity and adaptive capacity for Santiago de Chile. PLoS One, 2016, vol. 11, N 9. doi: 10.1371/ journal.pone.0162464

INSTITUTO NACIONAL DE ESTATÍSTICAS DO CHILE (INE). Resultados Censo 2017. 2017. Disponible en Internet: http://resultados.censo2017.cl/. Acceso en: 26 dic. 2019.

INSTITUTO NACIONAL DE PESQUISAS ESPACIAIS (INPE). Landsat. 2019. Disponible en Internet: http://www.dgi.inpe.br/documentacao/satelites/landsat. Acceso en: 26 dic. 2019.

MENDES, F.H. Tutorial para Iniciantes: software ENVI-met versão 3.1. 2014. Disponible en Internet: http://cmq.esalq.usp.br/wiki/lib/exe/fetch.php?media=publico:projetos:envi-met31_tutorial_iniciantes.pdf. Acceso en: 16 dic. 2019.

MENDES, F.H.; POLIZEL, J.L. \& SILVA FILHO, D.F. O efeito do vento nas quedas de árvores em Piracicaba/SP. Ciência e Natura, 2016, vol. 38, N 3, p. 1523-1535.

MENDES, F.H., SOUSA-CAMILO, A.S., LOPES, A.M.S., POLIZEL, J.L., SILVA FILHO, D.F. \& ROMERO, H. Comportamiento térmico de diferentes superficies urbanas durante un día cálido de verano. Revista Geográfica de Valparaíso, 2019, vol. 56, p. 1-8.

MIRANDA, F.M. ¿Ausencia de planificación urbana en Chile? Algunas reflexiones. Cybergeo: European Journal of Geography, 2017.

MUÑOZ, J.C.; BARTON, J.; FRÍAS, D.; GODOY, A.; BUSTAMANTE, W.; CORTÉS, S.; MUNIZAGA, M.; ROJAS, C. \& WAGEMNN, E. Ciudades y Cambio Climático en Chile: Recomendaciones desde la evidencia científica. Santiago: Comité COP25. Ministerio de Ciencia, Tecnología, Conocimiento e Innovación, 2019.

NERY, M.B.; SOUZA, A.A.L. \& ADORNO, S. Os padrões urbano-demográficos da capital paulista. Estudos Avançados, 2019, vol. 33, N 97, p. 5-36. https://doi.org/10.1590/s0103-4014.2019.3397.002

NURUZZAMAN, M. Urban heat island: causes, effects and mitigation measures-a review. International Journal of Environmental Monitoring and Analysis, 2015, vol. 3, N² 2, p. 67-73.

OKE, T.R. Boundary Layer Climates. London: Methuen and Co., 1978. 
PEEL, M.C.; FINLAYSON, B.L. \& MCMAHON, T.A. Updated world map of the Köppen-Geiger climate classification. Hydrology and Earth System Sciences Discussions, 2007, vol. 4, N², p. 439-473.

PIRES, E.G. \& FERREIRA JR., L.G. Mapeamento da temperatura de superfície a partir de imagens termais dos satélites Landsat 7 e Landsat 8. En: XVII Simpósio Brasileiro de Sensoriamento Remoto, 2015, João Pessoa. Proceedings... p. 7421-7428.

PRÉNDEZ, M.; ARAYA, M.; CRIOLLO, C.; EGAS, C.; FARÍAS, I.; FUENTEALBA, R. \& GONZÁLEZ, E. Urban Trees and Their Relationship with Air Pollution by Particulate Matter and Ozone in Santiago, Chile. En: HENRÍQUEZ, C. \& ROMERO, H. Urban Climates in Latin America. Cham: Springer International Publishing, 2019, p. 167-206.

ROMERO, H. Urban Climates and the Challenge of Sustainable Development of Chilean Cities. En: HENRÍQUEZ, C. \& ROMERO, H. Urban Climates in Latin America. Cham: Springer International Publishing, 2019, p. 207-256.

ROMERO, H. \& VÁSQUEZ, A. La comodificación de los territorios urbanizables y la degradación ambiental en Santiago de Chile. Scripta Nova, 2005, vol. 9, № 194, p. 1-68.

ROMERO, H.; IRARRÁZAVAL, F.; OPAZO, D.; SALGADO, M. \& SMITH, P. Climas urbanos y contaminación atmosférica en Santiago de Chile. EURE (Santiago), 2010, vol. 36, №109, p. 35-62.

ROMERO, H.; VÁSQUEZ, A.; FUENTES, C.; SALGADO, M.; SCHMIDT, A. \& BANZHAF, E. Assessing urban environmental segregation (UES). The case of Santiago de Chile. Ecological Indicators, 2012, vol. 23, p. 76-87.

ROMERO-LANKAO, P.; ROSAS-HUERTA, A.; HUGHES, S.; BORQUEZ, R.; GNATZ, D.M. Institutional capacity for climate change responses: An examination of construction and pathways in Mexico City and Santiago. Environmental and Planning C:Government and Policy, 2013, vol. 31, p. 785-805.

SADAVA, D.; HELLER, H.C.; ORIANS, G.H.; PURVES, W.K. \& HILLIS, D.M. Vida: A Ciência da Biologia - Volume 2. Evolução, Diversidade e Ecologia. 8ed. Porto Alegre: Artmed, 2009.

SANTIAGO. Gobierno Regional Metropolitano. Datos Geográficos. 2019. Disponible en Internet: https://www.gobiernosantiago.cl/datos-geograficos/. Acceso en: 27 dic. 2019.

SARRICOLEA ESPINOZA, P. \& MARTÍN-VIDE, J. El estudio de la isla de calor urbana de superficie del área metropolitana de Santiago de Chile con imágenes terra-MODIS y análisis de componentes principales. Revista de Geografía Norte Grande, 2014, № 57, p. 123-141.

SMITH, P. \& ROMERO, H. Factores explicativos de la distribución espacial de la temperatura del aire de verano en Santiago de Chile. Revista de Geografía Norte Grande, 2016, № 63, p. 45-62. 
SOUSA, S.B. \& FERREIRA, L.G. Análise da temperatura de superfície em ambientes urbanos: um estudo por meio de sensoriamento remoto no município de Goiânia, Goiás (2002-2011). Confins, $2012, N^{\circ} 15$.

STEWART, I.D. \& OKE, T.R. Local climate zones for urban temperature studies. Bulletin of the American Meteorological Society, 2012, vol. 93, N¹2, p. 1879-1900.

VÁSQUEZ, A.; DEVOTO, C.; GIANNOTTI, E. \& VELÁSQUEZ, P. Green Infrastructure Systems Facing Fragmented Cities in Latin America - Case of Santiago, Chile. Procedia Engineering, 2016, vol. 161, p. $1410-1416$. 